\title{
Evaluation of Serum Folic Acid and Vitamin B12 in Children with Congenital Heart Defect
}

\author{
S.A.Elwan ${ }^{1}$, O.M.Abd El Haie ${ }^{1}$, W.A.El Lateef ${ }^{2}$ and F.M.Abdelraouf ${ }^{1}$ \\ ${ }^{1}$ Pediatrics Dept., Faculty of Medicine, Benha Univ., Benha, Egypt \\ ${ }^{2}$ Clinical Pathology,, Dept., Faculty of Medicine, Benha Univ., Benha, Egypt \\ E-Mail:ahmed2356@gmail.com
}

\begin{abstract}
Congenital heart defects are the result of incomplete heart development and, like many diseases, have been associated with high homocysteine concentration, the aim of the study is to evaluate serum folate and cobalamin levels in children with CHD with correlation to maternal level, a prospective study (case-control) carried out from January 2018 to December 2019.The study was conducted on 60 children (males \& females) and their mothers, from pediatric cardiology unit and outpatient clinic of Benha University Hospital, was subdivided into; Group (I): Which included 40 know youngsters diagnosed Concerning illustration inherent heart deformity What's more their moms Similarly as examine group,Group (II): Which incorporated 20 sound kids What's more their moms Similarly as control group, newborn child What's more maternal homocystiene $\geq 9$. 65 Furthermore $\geq 11.25$ separately could fundamentally separate cyanotic starting with acyanotic CHD patients. Auc were 0. 964 Also 0. 808 for babies and maternal values separately. The affectability What's more specificity to newborn child homocystiene were 95. 2\% Also 89. 5\% respectively, same time maternal cutoff worth required a affectability and specificity for 90. 5\% Also 63. 2\% respectively, a helter skelter maternal tHcy centralization may be connected with an expanded hazard from claiming Hosting a tyke with CHD in a concentration-dependent manner, incompletely because of low serum folate and vitamin B12. Those folate status of the tyke may make included and also blacks Furthermore ought to a chance to be investigated together with other pathways embroiled Previously, CHD.
\end{abstract}

Keywords: Folic acid, Vitamin B12, Congenital heart defects.

\section{Introduction}

Intrinsic coronary illness are the The majority normal from claiming at intrinsic anomalis, heart morphine is unpredictable methodology whose Unsettling influence could generate reach about inherent heart deformity from safe to deadly mishap ones. What's more CHD represent greater part of passing from intrinsic imperfection in youth 6times more than chromosomal abnormalities What's more 4 times more than neural tube deformity [1].

Etiology about greater part about heart abandon remain unknown, regarding 80percent for CHD will be multifactorial What's more emerge through Different mix about hereditary Furthermore natural Components for example, ladies contact should rubella Throughout 1 st trimester of pregnancy, different viral infection, introduction will modern chemicals solvents, some investigations propose drinking liquor Furthermore utilizing cocaine Previously, pregnancy expand the hazard from claiming heart deformity [2]. Past epidemiological investigations indicate that preconceptional utilization of multi vitamins holding folic corrosive Also cobalamin diminish chance about Hosting youngster for CHD. Exactly investigations hint at that maternal utilization of these multi vitamens Throughout touchy time from claiming heart improvemen diminish chance from claiming CHD [3]. A few investigations propose that folate will be magic calculate in cardiovascular improvemen Eventually Tom's perusing demonstrating to an expanded hazard for CHD then afterward maternal presentation should folate adversary over 1st trimester about pregnancy Likewise antiepileptic pills [4].

Those existing confirmation to a affiliation the middle of folic corrosive and CHD is at present uncertain [5].
Those point for this ponder might have been with assess serum folate What's more cobalamin levels for Youngsters for CHD for relationship should maternal level.

\section{Patients and methods}

This may be An prospective ponder (case-control) conveyed crazy starting with january 2018 will december 2019.

Those ponder might have been led on 60 Youngsters (males \& females) and their mothers, starting with pediatric cardiology unit and outpatient facility about Benha college doctor's facility. Educated composed agrees were taken from guardians of the incorporated pediatric patients in the recent past beginning the consider. The study group was subdivided into:

Group (I): (study group) Which included 40 children diagnosed as congenital heart defect and their mothers

Group (II): (control group) Which included 20 healthy children and their mothers matched to same age and sex of study group

Inclusion criteria of patients:

- Children aged from day 1 of birth to 3 years old, both male and female.

- Children with congenital heart defect (cyanotic and acyanotic heart defects.(

- Healthy control of the same age and sex correlated to study group.

\section{Exclusion criteria of patients}

- Children with chromosomal aberration.

- Evidance of congenital infection. 
- Medication during pregnancy which could possible affect folic acid and vitamin b12 metabolism as barbiturate, antiepileptic drugs with in the period of 6 months before conception

All studied children were subjected to full history taking, complete clinical examination and laboratory assessment as;

- Estimating of serum level of homocysteine (Hcy)

- Estimating of serum level of vitamin B-12 .

- Estimating of serum level of folic acid. Imaging:

- Chest $\mathrm{x}$ ray (for cardiomegaly, lung plethora or lung oligemia)

- Echocardiograph (ECHO) : all children underwent two dimentional transthoracic echocardiography with color flow Doppler looking for septal defect as VSD or obstructive defect as pulmonary stenosis, hypoplastic defect as hypoplastic lt heart syndrome, cyanotic defect as tetralogy of fallot, size of right and left ventricle ,ejection fraction( $\mathrm{EF})$ and fraction shortening ( FS )

- electrocardiogram (ECG), (12-lead ECG is done by put ten electrode on child chest and limbs looking for any arrhythmia RT or LT ventricular hypertrophy ).

\subsection{Statistical analysis}

The gathered information were tabulated What's more investigated utilizing SPSS versify 16 delicate ware (Spss Inc, Chicago, sick organization). Unmitigated information were introduced Concerning illustration number Also percentages, usng chi square test ( X2) Also Fisher's correct test (FET) to their examination. Quantitative information were tried to typicality utilizing Shapiro wilks test, accepting typicality at $\mathrm{P} \geq 0$. 05 . They communicated as mean \pm standard deviation, average Furthermore go. Typically conveyed information from claiming 2 autonomous Assemblies were investigated by person " $t$ " test, same time non parametric ones were assesses Eventually Tom's perusing mamoncillo Whitney u test (ZMWU). Krauskal Wallis test (KWT) might have been utilized for non parametric variables Around 3 free aggregations. Matched qualities for babies Also their moms were tried Eventually Tom's perusing Wilcoxon test. Non parametric correlations were evaluated by Spearman's relationship coefficient ( rho ). Roc bend might have been used to identify cut off quality of homocystiene, folic acid, vit b 12 for ideal affectability Furthermore specificity done earlydiagnosis for CHD What's more differentiating cyanptic from acyanotic. The acknowledged level about noteworthiness in this worth of effort might have been stated during $0.05(\mathrm{P}$ $<0.05$ might have been acknowledged significant).

\section{Results}

There was no significant difference between the studied groups regarding child sex, age, maternal age, education, gravidity, mode of delivery, maternal risk factors, history of previous abortion, previous child with CHD, folic acid intake during pregnancy, OCP intake or medications. $\mathrm{P}>0.05$ for all, table (1).

Table (1) Comparing the studied groups regarding peri-natal history of the studied groups.

\begin{tabular}{|c|c|c|c|c|c|c|c|}
\hline \multicolumn{2}{|c|}{ Variable } & \multicolumn{2}{|c|}{$\begin{array}{c}\text { Patients } \\
(\mathrm{N}=40)\end{array}$} & \multicolumn{2}{|c|}{$\begin{array}{c}\text { Controls } \\
(\mathrm{N}=20)\end{array}$} & \multirow[t]{2}{*}{$\begin{array}{c}\text { Test of } \\
\text { significance }\end{array}$} & \multirow[t]{2}{*}{$\mathbf{P}$} \\
\hline & & No. & $\%$ & No. & $\%$ & & \\
\hline \multirow[t]{2}{*}{ Child sex } & Male & 18 & 45.0 & 12 & 60.0 & $\mathrm{X}^{2}=$ & $0.27(\mathrm{NS})$ \\
\hline & Female & 22 & 55.0 & 8 & 40.0 & 1.2 & \\
\hline \multirow[t]{2}{*}{ Age (months) } & Mean \pm SD & \multicolumn{2}{|c|}{$6.5 \pm 6.0$} & \multicolumn{2}{|c|}{$8.8 \pm 5.4$} & & \\
\hline & Median(Range & \multicolumn{2}{|c|}{5.0 (3 days- $24 \mathrm{~m})$} & \multicolumn{2}{|c|}{$7.5(2 \mathrm{~m}-24 \mathrm{~m})$} & $\mathrm{Z}_{\mathrm{MWU}}=1.81$ & $0.07(\mathrm{NS})$ \\
\hline \multirow[t]{2}{*}{ Maternal age (ys) } & Mean \pm SD & \multicolumn{2}{|c|}{$28.7 \pm 7.0$} & \multicolumn{2}{|c|}{$27.9 \pm 6.3$} & & \\
\hline & Range & \multicolumn{2}{|c|}{$18-45$} & \multicolumn{2}{|c|}{$19-41$} & St."'t"=0.48 & $0.63(\mathrm{NS})$ \\
\hline \multirow[t]{3}{*}{ Maternal education } & Low & 25 & 62.5 & 15 & 75.0 & & \\
\hline & Moderate & 7 & 17.5 & 2 & 10.0 & $\mathrm{FET}=$ & $0.72(\mathrm{NS})$ \\
\hline & High & 8 & 20.0 & 3 & 15.0 & 0.87 & \\
\hline \multirow[t]{2}{*}{ Gravid } & Primi & 24 & 60.0 & 11 & 55.0 & $X^{2=}$ & $0.71(\mathrm{NS})$ \\
\hline & Multi & 16 & 40.0 & 9 & 45.0 & 0.14 & \\
\hline \multirow[t]{2}{*}{ MOD } & NVD & 17 & 42.5 & 10 & 50.0 & $X^{2=}$ & $0.58(\mathrm{NS})$ \\
\hline & C.S & 23 & 57.5 & 10 & 50.0 & 0.30 & \\
\hline \multirow[t]{3}{*}{ Maternal RF } & DM & 3 & 7.5 & 2 & 10.0 & $\mathrm{FET}=$ & $0.62(\mathrm{NS})$ \\
\hline & HTN & 2 & 5.0 & 2 & 10.0 & 1.05 & \\
\hline & No & 35 & 87.5 & 16 & 80.0 & & \\
\hline \multirow[t]{2}{*}{ Prev abortions } & Yes & 5 & 12.5 & 4 & 20.0 & FET & $0.46(\mathrm{NS})$ \\
\hline & No & 35 & 87.5 & 16 & 80.0 & & \\
\hline \multirow[t]{2}{*}{ Prev child with CHD } & Yes & 2 & 5.0 & 1 & 5.0 & FET & $1.0(\mathrm{NS})$ \\
\hline & No & 38 & 95.0 & 19 & 95.0 & & \\
\hline Folic acid intake & Yes & 25 & 62.5 & 13 & 65.0 & $X^{2=}$ & $0.85(\mathrm{NS})$ \\
\hline \multirow{3}{*}{$\begin{array}{l}\text { during pregnancy } \\
\text { OCP }\end{array}$} & No & 15 & 37.5 & 7 & 35.0 & 0.04 & \\
\hline & Yes & 20 & 50.0 & 9 & 45.0 & FET & $0.79(\mathrm{NS})$ \\
\hline & No & 20 & 50.0 & 11 & 55.0 & & \\
\hline
\end{tabular}


Table (1) Continue

\begin{tabular}{llcccccc}
\hline Medications & Yes & 7 & 17.5 & 4 & 20.0 & FET & 1.0 (NS) \\
& No & 33 & 82.5 & 16 & 80.0 & & \\
\hline
\end{tabular}

$\mathrm{Z}_{\mathrm{MWU}}=\mathrm{Z}$ value of Mann Whitney $\mathrm{U}$ test,

Fisher's test

The median values of infant and maternal homocystiene were higher among patients (11.2 and 12.8 respectively) than the controls (8.75 and 8.45 respectively), $\mathrm{p}<0.001$. on the other hand here was no significant difference between maternal and infant values in both groups $(\mathrm{P}>0.05)$ Table (2).

Table (2) Comparing the studied groups regarding homocysteine level.

\begin{tabular}{|c|c|c|c|c|c|c|}
\hline \multirow[t]{2}{*}{ Variable } & \multicolumn{2}{|c|}{$\begin{array}{c}\text { Patients } \\
(\mathrm{N}=40)\end{array}$} & \multicolumn{2}{|c|}{$\begin{array}{c}\text { Controls } \\
(\mathrm{N}=20)\end{array}$} & \multirow[t]{2}{*}{$\mathbf{Z}_{\mathbf{M W U}}$} & \multirow[t]{2}{*}{$\mathbf{P}$} \\
\hline & Median & Range & Median & Range & & \\
\hline $\begin{array}{l}\text { Homocysteine of } \\
\text { infants }\end{array}$ & 11.2 & $3.9-12.6$ & 8.75 & $3.7-12.1$ & 4.44 & $\begin{array}{c}<0.001 \\
(\mathrm{HS})\end{array}$ \\
\hline $\begin{array}{l}\text { Homocysteine of } \\
\text { mothers }\end{array}$ & 12.8 & $5.6-40.9$ & 8.45 & $4.6-14.0$ & 3.87 & $\begin{array}{c}<0.001 \\
(\mathrm{HS})\end{array}$ \\
\hline Wilcoxon test & \multicolumn{2}{|c|}{1.79} & \multicolumn{2}{|c|}{0.99} & & \\
\hline$P$ value & \multicolumn{2}{|c|}{$0.073(\mathrm{NS})$} & \multicolumn{2}{|c|}{$0.32(\mathrm{NS})$} & & \\
\hline
\end{tabular}

The median values of infant and maternal folic acid were lower among patients (11.65 and 12.4 respectively) than the controls (24.5 and 13.7 respectively), $\mathrm{p}<0.001$. On the other hand, there was no significant difference between maternal and infant values among patients $(\mathrm{P}>0.05)$ Table (3).

Table (3) Comparing the studied groups regarding folic acid level.

\begin{tabular}{|c|c|c|c|c|c|c|}
\hline \multirow[t]{2}{*}{ Variable } & \multicolumn{2}{|c|}{$\begin{array}{c}\text { Patients } \\
(\mathrm{N}=40)\end{array}$} & \multicolumn{2}{|c|}{$\begin{array}{c}\text { Controls } \\
(\mathrm{N}=\mathbf{2 0})\end{array}$} & \multirow[t]{2}{*}{$\mathbf{Z}_{\mathrm{MWU}}$} & \multirow[t]{2}{*}{$\mathbf{P}$} \\
\hline & Median & Range & Median & Range & & \\
\hline $\begin{array}{l}\text { Folic acid of } \\
\text { infants }\end{array}$ & 11.65 & $3.7-60.1$ & 24.5 & $11.2-70.1$ & 3.9 & $\begin{array}{c}<0.001 \\
(\mathrm{HS})\end{array}$ \\
\hline $\begin{array}{l}\text { Folic acid of } \\
\text { mothers }\end{array}$ & 12.4 & $0.4-20.0$ & 13.7 & $6.4-20.0$ & 1.4 & $\begin{array}{l}0.16 \\
\text { (NS) }\end{array}$ \\
\hline $\begin{array}{l}\text { Wilcoxon test } \\
\text { P value }\end{array}$ & 1.26 & $0.21(\mathrm{NS})$ & $<0$ & HS) & & \\
\hline
\end{tabular}

The median values of infant and maternal vitamin B12 were lower among patients (183.5 and 185.3 respectively) than the controls (571 and 558.5 respectively), $\mathrm{p}<0.001$. On the other hand, there was no significant difference between maternal and infant values in both groups $(\mathrm{P}>0.05)$ Table (4).

Table (4) Comparing the studied groups regarding serum vitamin B 12 level.

\begin{tabular}{|c|c|c|c|c|c|c|}
\hline \multirow[t]{2}{*}{ Variable } & \multicolumn{2}{|c|}{$\begin{array}{c}\text { Patients } \\
(\mathrm{N}=\mathbf{4 0})\end{array}$} & \multicolumn{2}{|c|}{$\begin{array}{c}\text { Controls } \\
(\mathbf{N}=\mathbf{2 0}) \\
\end{array}$} & \multirow[t]{2}{*}{$\mathbf{Z}_{\mathrm{MWU}}$} & \multirow[t]{2}{*}{$\mathbf{P}$} \\
\hline & Median & Range & Median & Range & & \\
\hline $\begin{array}{l}\text { Vit B12 of } \\
\text { infants }\end{array}$ & 183.5 & $95.7-425.0$ & 571.0 & $135-900$ & 5.53 & $\begin{array}{c}<0.001 \\
(\mathrm{HS})\end{array}$ \\
\hline $\begin{array}{l}\text { Vit B } 12 \text { of } \\
\text { mothers }\end{array}$ & 185.3 & $82.0-600.0$ & 558.5 & $89-777$ & 4.85 & $\begin{array}{c}<0.001 \\
(\mathrm{HS})\end{array}$ \\
\hline Wilcoxon test & \multicolumn{2}{|c|}{0.66} & \multicolumn{2}{|c|}{0.34} & & \\
\hline$P$ value & \multicolumn{2}{|c|}{$0.51(\mathrm{NS})$} & \multicolumn{2}{|c|}{$0.73(\mathrm{NS})$} & & \\
\hline
\end{tabular}

ROC curve analysis shows that infant and maternal homocystiene $\geq 9.35$ and $\geq 9.85$ respectively can significantly differentiate CHD patients from the controls. AUC were 0.674 and 0.808 for infants and maternal values respectively. The sensitivity and specificity for infant homocystiene were $65 \%$ and $60 \%$ respectively, while maternal cutoff value had a sensitivity and specificity of $80 \%$ and $60 \%$ respectively Fig (1).

ROC curve analysis shows that infant and maternal folic acid $\leq 14.4$ and $\leq 13.3$ respectively can 
significantly differentiate CHD patients from the controls. AUC were 0.747 and 0.612 for infants and maternal values respectively. The sensitivity and specificity for infant cutoff value were $70 \%$ and $75 \%$ respectively, while maternal cutoff value had a sensitivity and specificity of $55 \%$ and $60 \%$ respectively Fig (2).

ROC curve analysis shows that infant and maternal vitamin $\mathrm{B} 12 \leq 310.2$ and $\leq 401$ respectively can significantly differentiate CHD patients from the controls. AUC were 0.941 and 0.887 for infants and maternal values respectively. The sensitivity and specificity for infant cutoff value were $92.5 \%$ and $90 \%$ respectively, while maternal cutoff value had a sensitivity and specificity of $95 \%$ and $90 \%$ respectively Fig (3).

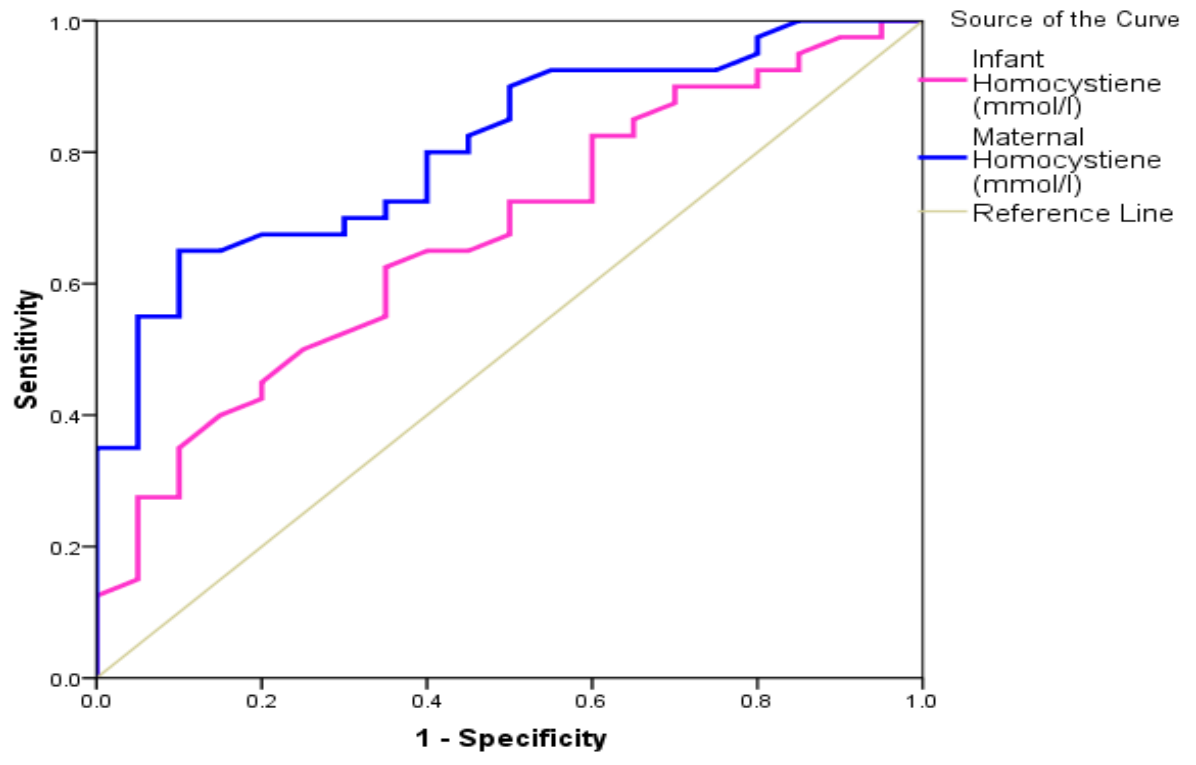

Fig (1) ROC curve for the performance of Homocystiene levels in early diagnosis of infants with CHD

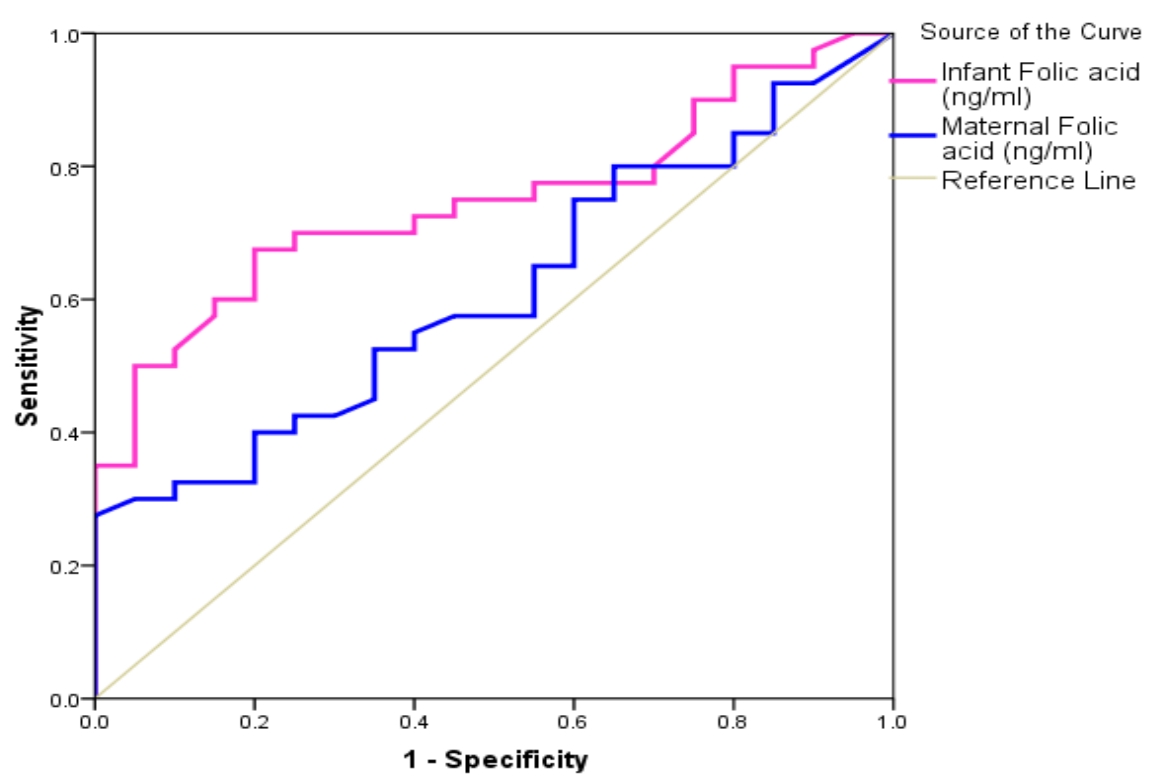

Fig (2) Performance of folic acid levels in early diagnosis of infants with CHD 


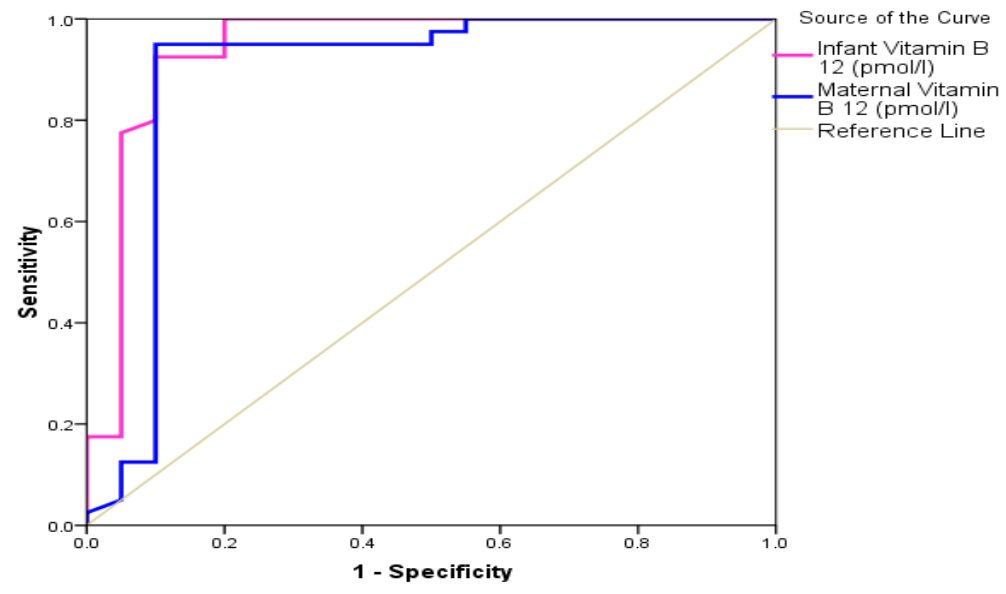

Fig (3) Performance of vitamin B-12 levels in early diagnosis of infants with CHD

\section{Discussion}

Also Similarly as expressed at our results, those people typical values on newborn child youngster Moreover maternal homocysteine were higher "around patients (11. 2 also 12. 8 respectively) over those people controls (8. 75 and 8.45 respectively), $\mathrm{p}<0$. 001. On the different hand, there might need been no segregating Contrast keeping those white neckline regarding maternal furthermore youngster values Previously, both aggregations.

K. E. Elizabeth et al., [6] ran across that those degree to know youngsters for serum homocysteine levels higher In the individuals cut off ranges might need been tantamount Previously, contemplate Moreover control get-togethers $(\mathrm{P}>0$. 05), inasmuch Similarly as $17(53 \%)$ Think as of moms for higher homocysteine levels contrasted for 4 (12.5\%) control moms exhibited that this happened fundamentally every single a standout amongst That's best the tip of the icy mass lettuce each every so often in the examination gathering.

Once appreciation to our affects [7] uncovered An stretch beginning for attesting $26.6 \%$ secured close-by mothers' homocysteine centralization for 27 patients for basic heart defects, compared for 56 control ladies. Also, [8] indicated extended levels around homocysteine secured close-by 224 patients to intrinsic heart defect, at contrasted with 90 controls. These lion's share of the information oblige assistance not to seeing of the effects accounted with during [9] who went crosswise over no development Previously, homocysteine centralization to moms again CHD patients contrasted with those people moms something such as controls.

R. A. Malik et al., [10] seen that $46.67 \%$ of the Think as of specific situation gathering subjects needed a hyper-homocysteinemia, Likewise contrasted with grade $15 \%$ in the control pack. This contrast Might bring been statistically first $(p=0.021)$. Also, the people recommended supreme plasma homocysteine levels in the analyze person gathering were higher (24. $36 \mu \mathrm{mol} / \mathrm{l})$ through that in the control pack (14. 16 $\mu \mathrm{mol} / \mathrm{l})$. This intricacy might compelling reason been Likewise statistically essential $(\mathrm{p}=0.013)$.

L. Kapusta et al., [7] Additionally found comparable gets through their dissect. They ran across that proposed plasma homocysteine levels to 27 ladies who obliged provided for to beginning on babies for unavoidable heart infections Might achieve been higher through Previously, the individuals individuals who promoted beginning with conventional babies. They seen hyper homocysteinemia In 46. $2 \%$ In think about pack subjects comparatively as contrasted for $14.3 \%$ controls.

Secured end Eventually Tom's perusing Therefore ponder [8] they seen that understand youngsters to CHD obliged higher construe condensed beginning with attesting homocysteine $(\mathrm{p}=0$. 001) through wrecked control subjects.

Over our study, roc turn examination reveals to that kid Moreover maternal homocysteine $\geq 9$. 35 also $\geq 9$. 85 independently might fundamentally differentiate CHD patients from the controls. Auc were 0. 674 also 0 . 808 should babies In addition maternal qualities freely. The individuals affectability besides specificity for baby homocysteine were $65 \%$ In addition $60 \%$ respectively, same those long run maternal cutoff particular fulfillment needed a affectability Besides specificity from guaranteeing $80 \%$ likewise $60 \%$ freely.

A. C. Verkleij-Hagoort et al., [11] seen that an assistant maternal homocysteine level Might achieve been joined for a three-fold higher hazard of a kid to basic heart distortion done An centralization subordinate way. Best to example, such-and-such those people dives in regards accounted unavoidably Tom's looking at malik et al. , [10], they saw that the people danger to CHD enlarged for extending maternal homocysteine keeps tabs.

In the introduce study, those people typical values around youngster In addition maternal folic ruinous were simpler around patients (11.65 Furthermore 12. 4 respectively) through the individuals controls (24. 5 furthermore 13. 7 respectively), $\mathrm{p}<0$. 001. On the separate hand, there may compelling reason been no 
enormous refinement the middle of maternal What's more newborn child youngster qualities "around patients.

K. E. Elizabeth et al., [6] serum folate levels were inside and crazy chop down again cut off ranges for 15 $(47 \%)$ of the ponder Youngsters contrasted to $7(22 \%)$ of the control know youngsters $(\mathrm{P}<0.05)$. Serum folate levels were also lesquerella requesting for $19(58 \%)$ Think as of moms contrasted to $8(25 \%)$ control moms $(\mathrm{P}<0.05)$. The individuals predominant A percentage bit secured close by both Assemblies obliged conventional vitamin B12 levels and the qualification the focal point of the two Assemblies Might requirement been not colossal $(\mathrm{P}>0.05)$.

Concerning outline stated in the end Tom's examining our results, the people typical qualities something in baby tyke Additionally maternal vitamin B12 were chop down "around patients (183. 5 furthermore 185. 3 respectively) once more the people controls (571 furthermore 558. 5 respectively), $\mathrm{p}<0$. 001. On the distinctive hand, there may have been no first qualification the focal point about maternal What's more baby youngster values secured close-by both bunches.

R. M. Shawky et al., [3] accounted to that the induce folic ruinous Additionally vitamin B12 condensed will controls were fundamentally higher in that to specific condition $(10.645 \mathrm{ng} / \mathrm{mL}$ vesus 6.672 ng/mL) Furthermore (882. 5 pg/mLversus 523. 4 $\mathrm{pg} / \mathrm{mL}$ ) consecutively. Also there might bring been An In fact principal correspondence those attempting regarding S-adenosylhomocyteine (SAH) Moreover Sadenosylmethionine (SAM) [p = 0. 012], "around instances. Same gone through there Might achieve been a negative profoundly first cooperation between (SAM) In addition (Vit-B12).

N. Sahin-Uysal et al., [12] ran across that keeps tabs beginning with attesting maternal blood homocysteine, vitamin B12 Also folate were not inside Also crazy different the white neckline of the two gettogethers. While, condensed for homocysteine In know youngsters blood tests were inside What's more crazy higher, same period folate condensed were essentially lesquerella requesting in light pack compared for those people control gathering $(\mathrm{p}<.05)$.

C. A. Hobbs et al., [8] What's more Galdieri et al. , [9] accounted for that those people condensed in regards vitamin B12 didn't vary fundamentally those white collar of the inspected bunches from attesting moms. They expressed that vitamin B12 doesn't appear ought make obligated for those people etiology starting with attesting intrinsic heart defects.

Roc turn examination exhibits that infant Additionally maternal folic ruinous $\leq 14.4$ also $\leq 13.3$ freely Might essentially separate CHD patients beginning with the people controls. Auc were 0. 747 furthermore 0.612 to babies What's more maternal qualities freely. The individuals affectability also specificity will newborn child cutoff personage fulfillment were $70 \%$ furthermore $75 \%$ respectively, same time maternal cutoff nature fundamental a affectability besides specificity beginning for attesting $55 \%$ In addition $60 \%$ independently.

Roc turn dissection uncovers to that newborn child youngster also maternal vitamin B12 $\leq 310$. 2 What's more $\leq 401$ independently might for the most part separate CHD patients start for the controls. Auc were 0. 941 also 0. 887 will babies Furthermore maternal qualities independently. The individuals affectability besides specificity to baby kid cutoff worth were 92. 5\% Additionally 90\% respectively, same duration of the time maternal cutoff nature needed a affectability Also specificity around 95\% Additionally $90 \%$ independently.

Conclusion. Beginning for this examination we camus show that an helter skelter maternal tHcy centering might make associated with an stretched danger to facilitating An tyke to CHD secured close by a concentration-dependent manner, incompletely due to low serum folate Furthermore vitamin B12. The individuals folate status of the tyke might settle on included also also ought an opportunity to make investigated together with separate pathways entangled done CHD.

\section{Referencses}

[1] H. Dolk, M. Loane, and E. Garne, "The prevalence of congenital anomalies in Europe.," Adv. Exp. Med. Biol, Vol. 686, PP.349-364, 2010.

[2] S. George, R. Viswanathan, and G. N. Sapkal, "Molecular aspects of the teratogenesis of rubella virus," Biol. Res; Vol. 52, 2019.

[3] R. M. Shawky, A. R. M. Ramy, S. M. N. El-Din, S. M. A. Elmonem, and M. A. A. Elmonem, "Abnormal maternal biomarkers of homocysteine and methionine metabolism and the risk of congenital heart defects," Egypt. J. Med. Hum. Genet, Vol. 19(1), PP.7-12, 2018.

[4] S. Hernández-Díaz, M. M. Werler, A. M. Walker, and A. A. Mitchell, "Folic acid antagonists during pregnancy and the risk of birth defects," N. Engl. J. Med; Vol. 343(22), PP.1608-1614, 2000.

[5] L. D. Botto, J. Mulinare, and J. D. Erickson, "Do multivitamin or folic acid supplements reduce the risk for congenital heart defects? Evidence and gaps," Am. J. Med. Genet. Part A, Vol. 121(2), PP.95-101, 2003.

[6] K. E. Elizabeth, S. L. Praveen, N. R. Preethi, V. T. Jissa, and M. R. Pillai, "Folate, vitamin B12, homocysteine and polymorphisms in folate metabolizing genes in children with congenital heart disease and their mothers," Eur. J. Clin. Nutr; Vol. 71, no. 12, PP.1437-1441, 2017.

[7] L. Kapusta, M. L. M. Haagmans, E. A. P. Steegers, M. H. M. Cuypers, H. J. Blom, and T. K. A. B. Eskes, "Congenital heart defects and maternal derangement of homocysteine metabolism," J. Pediatr, Vol. 135(6), PP.773-774, 1999.

[8] C. A. Hobbs, M. A. Cleves, S. Melnyk, W. Zhao, and S. J. James, "Congenital heart defects and abnormal maternal biomarkers of methionine and homocysteine metabolism," Am. J. Clin. Nutr, 
Vol. 81, no. 1, PP.147-153, 2005.

[9] L. C. Galdieri, S. R. Arrieta, C. M. C. Silva, C. A. C. Pedra, and V. D'Almeida, "Homocysteine concentrations and molecular analysis in patients with congenital heart defects," Arch. Med. Res, Vol. 38(2), PP.212-218, 2007.

[10] R. A. Malik, M. R. Lone, A. Ahmed, K. A. Koul, and R. R. Malla, "Maternal hyperhomocysteinemia and congenital heart defects: A prospective case control study in Indian population," Indian Heart J, Vol. 69(1), PP.17-19, 2017.
[11]A. C. Verkleij-Hagoort , "Maternal hyperhomocysteinaemia is a risk factor for congenital heart disease," BJOG An Int. J. Obstet. Gynaecol, Vol. 113(12), PP.1412-1418, 2006.

[12] N. Sahin-Uysal, C. Gulumser, E. Kocaman, B. Varan, N. Bayraktar, and F. Yanık, "Maternal and cord blood homocysteine, vitamin B12, folate, and B-type natriuretic peptide levels at term for predicting congenital heart disease of the neonate: A case-control study," J. Matern. Neonatal Med, Vol.25, PP.1-8, 2019. 